\title{
Evaluating the serological status of COVID-19 patients using an indirect immunofluorescent assay, France
}

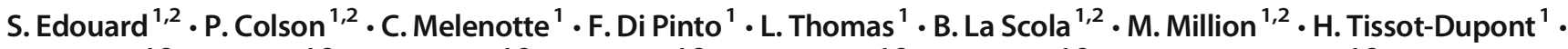 \\ P. Gautret ${ }^{1,3} \cdot$ A. Stein ${ }^{1,2} \cdot$ P. Brouqui ${ }^{1,2} \cdot$ P. Parola ${ }^{1,3} \cdot$ J.-C. Lagier ${ }^{1,2} \cdot$ D. Raoult ${ }^{1,2} \cdot$ Michel Drancourt $^{1,2}$
}

Received: 24 September 2020 / Accepted: 5 November 2020 / Published online: 11 November 2020

(C) Springer-Verlag GmbH Germany, part of Springer Nature 2020

\begin{abstract}
An indirect in-house immunofluorescent assay was developed in order to assess the serological status of COVID-19 patients in Marseille, France. Performance of IFA was compared to a commercial ELISA IgG kit. We tested 888 RT-qPCR-confirmed COVID-19 patients (1302 serum samples) and 350 controls including 200 sera collected before the pandemic, 64 sera known to be associated with nonspecific serological interference, 36 sera from non-coronavirus pneumonia and 50 sera from patient with other common coronavirus to elicit falsepositive serology. Incorporating an inactivated clinical SARS-CoV-2 isolate as the antigen, the specificity of the assay was measured as $100 \%$ for $\operatorname{IgA}$ titre $\geq 1: 200,98.6 \%$ for IgM titre $\geq 1: 200$ and $96.3 \%$ for IgG titre $\geq 1: 100$ after testing a series of negative controls. IFA presented substantial agreement $(86 \%)$ with ELISA EUROIMMUN SARS-CoV-2 IgG kit (Cohen's Kappa $=0.61)$. The presence of antibodies was then measured at $3 \%$ before a 5 -day evolution up to $47 \%$ after more than 15 days of evolution. We observed that the rates of seropositivity as well as the titre of specific antibodies were both significantly higher in patients with a poor clinical outcome than in patients with a favourable evolution. These data, which have to be integrated into the ongoing understanding of the immunological phase of the infection, suggest that detection anti-SARS-CoV-2 antibodies is useful as a marker associated with COVID-19 severity. The IFA assay reported here is useful for monitoring SARS-CoV-2 exposure at the individual and population levels.
\end{abstract}

\section{Introduction}

The SARS-CoV-2 is a coronavirus belonging to the genus Betacoronavirus that emerged in humans in December 2019 [1]. It was first described in China before spreading and being classified as a pandemic [2]. It causes a respiratory disease known as COVID-19 that is usually mild but can result in a severe and even life-threatening pneumonia, particularly in elderly people [2-4]. On 21 September 2020, 31,033,397 SARSCoV-2 infections and 960,736 associated deaths had been reported worldwide (https://coronavirus.jhu.edu/map.html).

To date, the virological diagnosis of infections by SARS$\mathrm{CoV}-2$ has been essentially based on real-time reverse transcription PCR [5]. This virus has been shown to elicit specific

Michel Drancourt

michel.drancourt@univ-amu.fr

1 IHU-Méditerranée Infection, 19-21 boulevard Jean Moulin, 13005 Marseille, France

2 Aix Marseille Univ., IRD, AP-HM, MEPHI, Marseille, France

3 Aix Marseille Univ., IRD, AP-HM, SSA, VITROME, Marseille, France antibodies during the course of infection [6, 7]. This serological response has mainly been analysed using enzyme-linked (ELISA) or chemiluminescence immunoassays among exposed populations in China and neighbouring countries. Previous studies showed that specific IgG, IgM and IgA were produced in response to the infection [7]. The kinetics of these three classes of antibodies have been described, yet correlations with the clinical outcome of the patients has been poorly reported [7].

In this study, we are reporting our experience to develop an indirect immunofluorescent assay (IFA) for the detection of antiSARS-CoV-2 antibodies that we implemented before any other serological test was available in France. Performance of IFA was compared to a commercial ELISA anti-SARS-CoV-2 IgG kit when they became available. We found significant differences in the rates of seropositivity and antibody titres between groups of patients depending on their clinical outcome.

\section{Patients and methods}

Study design An in-house IFA was developed to assess the serological status of a cohort of patients with confirmed SARS-CoV-2 infection at the Institut Hospitalo- 
Universitaire (IHU) Méditerranée Infection in Marseille, France [4]. All patients presenting symptoms compatible with COVID-19 and contacts of suspected and confirmed COVID19 cases were tested using a SARS-CoV-2-specific RT-qPCR assay $[4,8]$. Treatment with hydroxychloroquine (HCQ) associated with azithromycin (AZ) was proposed to all RTqPCR-positive patients who enrolled on a voluntary basis if they did not present contraindications [4]. Patients were followed up on an out-patient basis at our day care hospital or were hospitalised in the infectious disease units of the IHU, in intensive care units or in other medical departments of the Assistance Publique-Hôpitaux de Marseille, depending on the severity of the disease. We included in the present study all patients from the previous study by Million et al. for whom $\geq$ 1 serum sample was available for serological testing as part of the routine care of these patients. Meanwhile, the sera from 350 controls randomly selected were tested to evaluate specificity of IFA. Also, we further compared the specificity and sensitivity of IFA to a SARS-CoV-2 IgG ELISA which became commercially available 3 months after we set up IFA. All the sera were tested retrospectively. The time of serum collection was determined relative to the date of the onset of symptoms. The non-interventional nature of this study was approved by the Ethical Committee of the IHU Méditerranée Infection under no. 2020-13.

Case definition SARS-CoV-2 infection was defined by clinical, radiological, and microbiological criteria as previously reported [3, 4]. Briefly, the national early warning score (NEWS) for COVID-19 was used for the classification of clinical presentation of patients. This score was based on 6 physiological parameters including respiratory rate, oxygen saturations, temperature, systolic blood pressure, heart rate and level of consciousness to predict deterioration risk in acute ill patients. Three risk categories were defined for clinical deterioration: low score (NEWS 0-4), medium score (NEWS 5-6), and high score (NEWS $\geq 7$ ). Virological evidence of the infection was based on a positive RT-qPCR on a nasopharyngeal sample or another respiratory sample. Pulmonary involvement was evaluated by chest low-dose computed tomography for all patients. Five groups of patients were constituted according to the following criteria [4]: (1) patients with mild disease and good clinical and virological outcome (GO; $n=681)$; (2) patients with poor virological outcome defined by persistence at day 10 or more of viral RNA load in respiratory samples (PVirO; $n=100)$; (3) patients who received $\mathrm{HCQ}+\mathrm{AZ}$ treatment for more than 3 days, with poor clinical outcome requiring prolonged hospitalisation for 10 days or more despite 3 days or more of $\mathrm{HCQ}+\mathrm{AZ}$ treatment (PClinO1; $n=53$ ); (4) patients who received HCQ + AZ treatment less than 3 days, with poor clinical outcome requiring prolonged hospitalisation for 10 days or more (PClinO2; $n=25)$; (5) patients with poor clinical outcome requiring prolonged hospitalisation for 10 days or more leading to death (PClinO3; $n=29$ ) including 16 who received HCQ + AZ treatment. Main characteristics of the patients in each group are summarised in Table 1.

Indirect immunofluorescence assay Anti-SARS-CoV-2 antibodies were detected using an in-house indirect immunofluorescence assay (IFA), as previously described [9]. Vero E6 cells (ATCC CRL-1586, Rockville, MD, USA) infected with the SARS-CoV2 strain IHU-MI2 (full genome sequence of this strain was deposited under the European Molecular Biology Laboratory EMBL project accession no. PRJEB38023) [10] were used as the antigen. Infected cells were harvested between 24 and $48 \mathrm{~h}$ post-inoculation when cytopathic effect began to be observed, before massive cell lysis. Infected cells were washed with sterile phosphate buffered saline (PBS) (Oxoid, Dardilly, France) and inactivated using $5 \%$ paraformaldehyde. The antigen $(50 \mathrm{~nL})$ was spotted on each well of a 18-well microscope glass slide using Echo 525 Liquid Handler instruments (Labcytes, Cannock, UK) that uses acoustic energy to transfer liquid from a 96 -well plate containing the antigen to slides. Fifty nanolitres of uninfected Vero cells were also spotted on each well as a negative control and a clinical isolate of Staphylococcus aureus (identified by matrix-assisted laser desorption ionisation time of flight mass spectrometry) [11] was spotted on each well in order to ensure further serum deposition, as previously described [12]. Each slide was air dried, fixed in acetone for $10 \mathrm{~min}$ and conserved at $4{ }^{\circ} \mathrm{C}$ in the dark.

In a first step, each serum sample was screened for the presence of anti-SARS-CoV-2 antibodies using the IFA, as previously described [9]. Serum samples were heatdecomplemented for $30 \mathrm{~min}$ at $56{ }^{\circ} \mathrm{C}$, diluted in 3\% PBSmilk and $25 \mu \mathrm{L}$ of a 1:50 dilution and a 1:100 dilution were pipetted onto a 18 -spot slide then incubated for $30 \mathrm{~min}$ at $37^{\circ} \mathrm{C}$ in the dark to be screened for the detection of total immunoglobulin (IgT). After washing thrice, the slides with sterile PBS for 10 min, $25 \mu \mathrm{L}$ of total FITC-conjugated IgT anti-human immunoglobulin (Bio-Rad, Marnes-la-Coquette, France) with $0.5 \%$ Evans blue (Bio-Rad) were incubated for $30 \mathrm{~min}$ at $37^{\circ} \mathrm{C}$. After washing, slides were examined under a fluorescence microscope (AxioSkop 40, Zeiss, Marly le Roi, France). In a second step, all the serum samples screened positive at a 1:100 dilution were quantified for IgG, IgM and IgA as reported above, except that serum samples were diluted up to 1:1600 for IgA and IgM and 1:3200 for IgG; and antiIgG, anti-IgM and anti-IgA conjugates were used (Bio-Rad). Serum samples exhibiting positivity at 1:3200 were further tested up to $1: 25,600$. Serum samples exhibiting positivity at 1:3200 were further tested up to $1: 25,600$. Antibody titre was determined by the last dilution with detected fluorescence. Reading of slide was performed in duplicate by two experienced laboratory technicians or medical microbiologists. In 


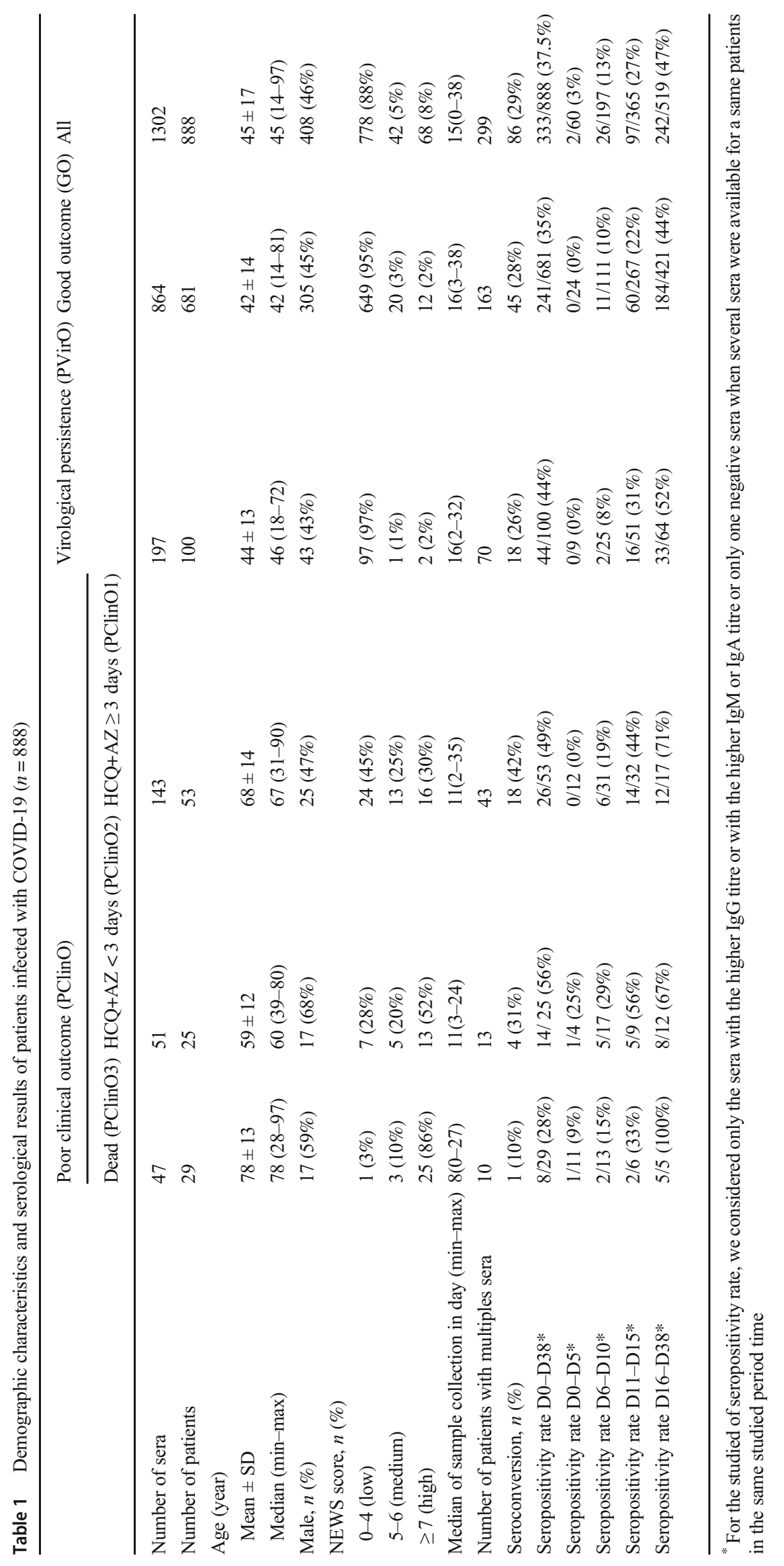


case of discrepancy, a third operator read the slide. A serum sample collected from one patient who was positive by SARSCoV-2 RT-qPCR and exhibiting IgG, IgM and IgA titres of 1:400, 1:100 and 1:100, respectively, was anonymised and used as a positive control. It was used on each slide for screening and on each run for antibody quantification allowing to daily endure the robustness of the technique and validate any new lot of antigen. A negative serum collected in December 2019 from a patient and PBS-milk 3\% were used as negative controls on each slide screened. In order to interpret the IFA, any serum sample exhibiting $\operatorname{IgG} \geq 1: 100$ with or without IgM and/or $\operatorname{IgA} \geq 1: 50$ was considered as positive, as well as any serum sample exhibiting isolated IgM or IgA 1:200 (Fig. 1).

Serum samples The specificity of the IFA was evaluated by testing four series of serum samples. Negative control samples $(n=200)$ had been collected from patients between November and December 2018 (before the COVID-19 epidemics in France). Furthermore, 150 sera known to be associated with nonspecific serological interference were collected from 14 patients diagnosed with Epstein-Barr virus infection; eight patients diagnosed with cytomegalovirus infection; seven patients diagnosed with A hepatitis virus infection; 10 patients diagnosed with toxoplasmosis; and 25 patients diagnosed with $\mathrm{E}$ hepatitis virus infection. Serum samples were also collected from 50 patients diagnosed with coronavirus NL63, OC43, 229E or HKU1, as well as 36 sera collected from patients diagnosed with noncoronavirus pneumonia, including 14 Mycoplasma pneumoniae infections, 10 Legionella pneumophila infections and 12 Chlamydia pneumoniae infections, in order to assess for potential cross-reactivity. We evaluated repeatability of IFA by testing 5 sera in triplicate by a same operator and reproducibility testing 5 sera by 2 independent operators.

ELISA To compare our IFA with commercial ELISA IgG, we randomly selected 70 sera with possible cross-reactivity (including 45 sera with possible nonspecific serological interference and
25 sera from patients diagnosed with common others human coronavirus), 30 sera collected before the pandemic and 100 sera from our cohort of SARS-CoV-2-infected patients among all the sera that we tested by IFA. Positive RT-qPCR was considered as definite criteria for SARS-CoV-2 infection and the 2 serological techniques were compared in these 2 groups of patients. EUROIMMUN® SARS-CoV-2 IgG ELISA (Euroimmun France ${ }^{\circledR}$, Bussy Saint-Martin, France) using recombinant S1 protein as antigen was performed using Elispeed DUO system (Euroimmun France ${ }^{\circledR}$ ) according to the manufacturer's recommendations. The ratio (AUC sample/AUC calibrator) was interpreted according to the manufacturer's recommendations: $<0.8$ negative; $\geq 0.8$ to $<1.0$ undetermined (grey zone); $\geq 1.1$ positive. We considered results in grey zone as negative for statistical analyses.

Statistical analysis To avoid bias in data analysis, we studied the serological response according to the time of sampling of the sera related to the date of the onset of symptoms. The analysis of sera was divided into different time intervals (D0-D5, D6-D10, D11-D15 and D16-D38). For the study of rates of seropositivity and for the comparison of IgG titre, we considered only the sera with the higher IgG titre or with the higher IgM or IgA titre when several sera were available for a same patient. For the data comparisons and statistical analyses, Fisher's exact test, the chi-squared test, MannWitney test and standard statistical software (GraphPad Prism 7) were used. The agreement rate and Cohen's Kappa value were determined for agreement between ELISA and IFA. A $p$ value $<0.05$ was considered statistically significant. ROC curves were calculated using GraphPad Prism 7.

\section{Results}

IFA The results of IFA assay specificity are summarised in Table 2. In the negative control group of 200 serum samples
Fig. 1 Immunofluorescence assay of serum sample from a COVID-19-infected patient. Each well of glass slides was spotted with SARS-Cov-2 antigen (A), non-infected VERO cells (B) and S. aureus antigen (C). Left panel, patient's serum with anti-SARS$\mathrm{CoV}-2$ total immunoglobulins detectable at dilution 1:100. Patient presented IgG titre at 1:400, IgM titre at 1:50 and IgA titre at 1:100. Right panel, negative control serum. Slides were observed using a Zeiss microscope, objective $\times 40$

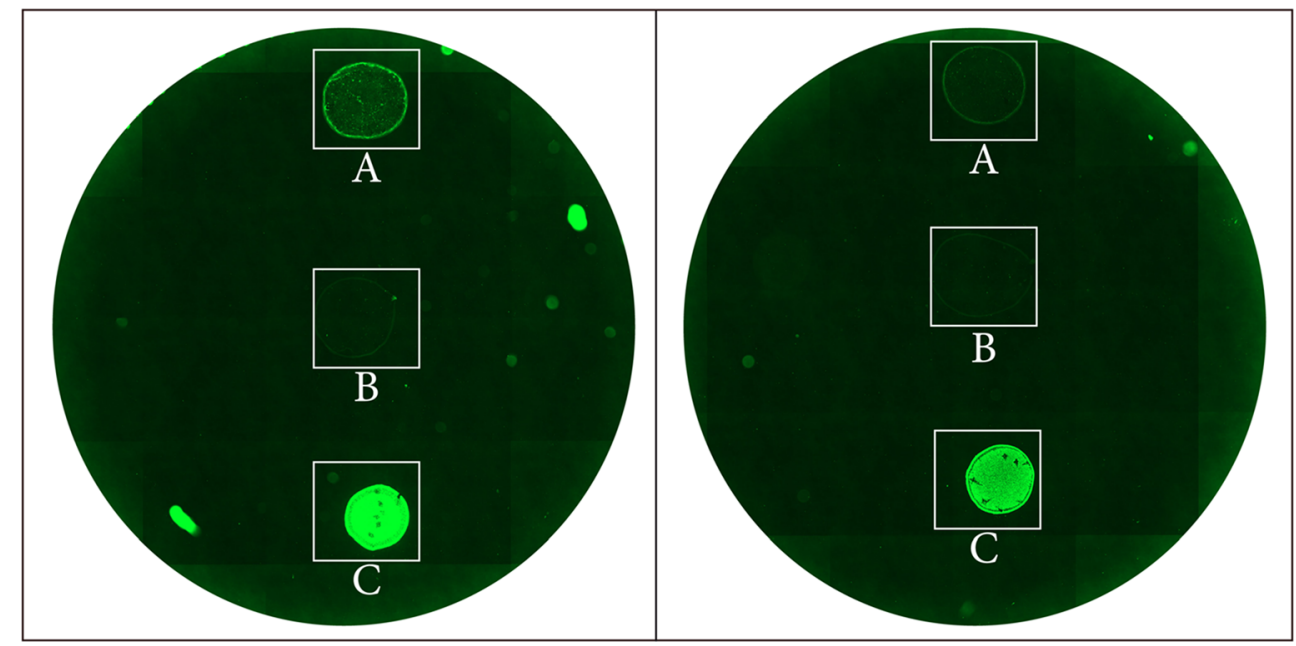




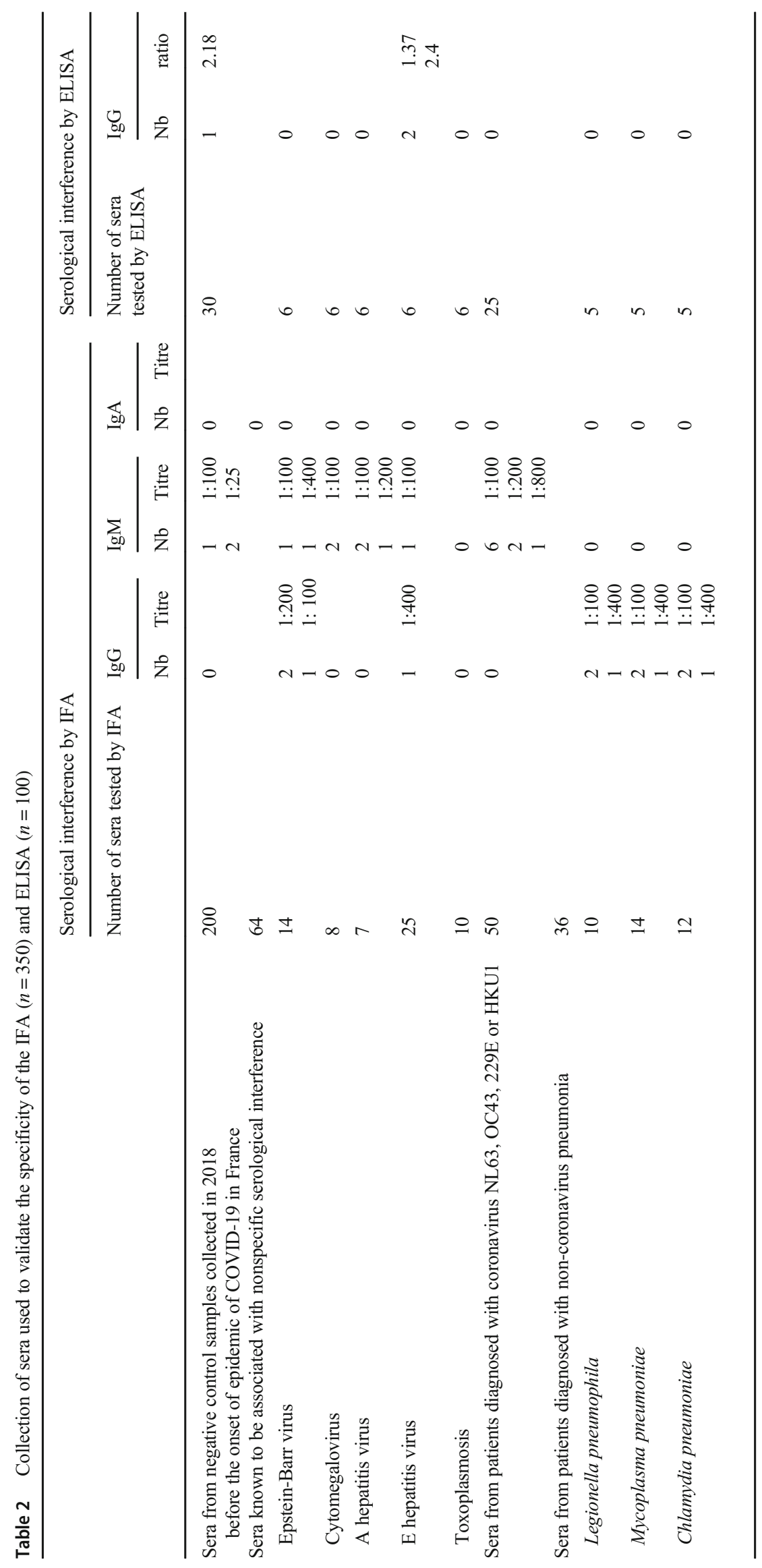


collected from patients in November and December 2018 before the emergence of COVID-19 in France, no IgG and no IgA were detected and three samples exhibited a IgM titre of 1:25 for two samples and 1:100 for one sample. In the group of 64 sera samples known to yield cross-reactivities, four samples exhibited $\operatorname{IgG}$ titre $\geq 1: 100$ and 8 samples exhibited IgM titre $\geq 1: 100$. Of the 50 sera samples collected from patients diagnosed with another coronavirus other than COVID-19, none reacted in $\operatorname{IgG}$, none reacted in $\operatorname{IgA}$ and 9 reacted in IgM with titre $\geq 1: 100$. Also, among 36 sera collected from patients diagnosed with non-coronavirus pneumonia, nine yielded an $\operatorname{IgG}$ titre $\geq 1: 100$ but did not react for $\operatorname{IgM}$ and IgA. Overall, 13/350 sera samples yielded a false positivity of $\operatorname{IgG} \geq 1: 100$, yielding a $96.3 \%$ specificity for $\operatorname{IgG}$; and $5 /$ 350 serum samples yielded a false positivity of $\operatorname{IgM} \geq 1: 200$, yielding a specificity of $98.6 \%$ for IgM. Specificity of $\operatorname{IgA}$ titre of 1:200 was $100 \%$. Combination of criteria $\operatorname{IgG} \geq$ 1:100 with or without IgM and/or IgA $\geq 1: 50$ showed $96 \%$ specificity (Fig.S1). Reproducibility and repeatability of the assay were evaluated to $100 \%$ and $100 \%$ for screening and to $100 \%$ and $93 \%$ for quantification if we tolerate a deviation of one dilution.

\section{Comparison between IFA and ELISA for the detection of SARS-}

CoV-2 IgG Specificity and sensitivity of ELISA IgG were evaluated to $97 \%$ and $45 \%$, respectively, compare to $93 \%$ and $41 \%$ for our in-house IFA among the 200 sera tested with both techniques. Three sera among the negative controls were positive for ELISA and 7 for IFA, respectively. Discordant results were found for $15 \%$ (31/200) of the sera; 17 sera were positive only by IFA (including 7 false positive) and 14 sera were positive only by ELISA (including 3 false positive). IFA presented substantial agreement $(86 \%)$ with ELISA EUROIMMUN SARS-CoV-2 IgG kit (Cohen's Kappa = 0.61 ). If we considered only sera collected at least 14 days after the onset of symptoms of SARS-CoV-2-infected patients $(n=56)$, sensitivity was $67 \%$ with ELISA versus $64 \%$ with IFA that is not significantly different.

Serological response of infected patients We then evaluated the serological response in a collection of 1302 serum samples from 888 patients infected with SARS-CoV-2 between 12 March and 17 April 2020 [4]. SARS-CoV-2 infection was confirmed by positive RT-q on respiratory specimens for all these patients with a median $\mathrm{Ct}$ value of 25.65 (range 12.5$35)$. This cohort, which included 408 men (46\%), had a median age of 45 years (range, 14-97 years). Median age of patients with poor clinical outcome $(\mathrm{PClinO} 1, \mathrm{PClinO} 2$, PClinO3) was significantly higher than the median age of patients from PVirO and GO group $(p<0.0001)$. Most of the patients $(778 / 888,88 \%)$ presented a low NEWS score $(\leq 4)$ and 24 patients were asymptomatic. Patients from the 3 groups with poor clinical outcome presented significant higher NEWS score than patients from $\mathrm{PVirO}$ and GO group $(p<0.0001$ and $p<0.0001$, respectively) (Table 1$)$. Serum samples had been collected at a median time of 15 days (range, 0-38 days) after onset of symptoms. Seventy (5.4\%) sera were collected between D0 and D5, 238 (18.3\%) between D6 and D10, 395 (30.3\%) between D11 and D15 and 599 (46\%) between D15 and D38. At least one positive serology (with our defined criteria) was found in 330 patients, leading to a seropositivity of $37.2 \%$. The time distribution of positive serum samples was as follows: $3 \%(2 / 60)$ between D0 and D5, $13 \%$ (26/197) between D6 and D10, 27\% (97/365) between D11 and D15 and 47\% (242/519) after D16. Multiple sera were available for 299 patients. Among them, we observed $88(29 \%)$ seroconversions with $6(7 \%)$ patients seroconverting between D6 and D10, 25 (28\%) between D11 and D15 and 57 (65\%) after D16. Only two patients were observed to be positive within 5 days after onset of the illness, one patient exhibited $\operatorname{IgG}$ titre 1:100 and another patient with $\operatorname{IgG}$ titre at $1: 1600$ and $\operatorname{IgA}$ at 1:100. Seroconversion occurred earlier in patients with poor clinical outcome (PClinO) with a median of 13 days compared to patients with good outcome for whom seroconversion occurred with a median of 19 days ( $p=$ $0.0009)$. We represented the kinetics of the antibodies in our cohort of sera collected before D30 $(n=1291)$ in Fig. 2. An earlier and higher increase of IgG, IgM and IgA was found in patients with poor outcome compared to patients with good outcome and with virological persistence.

Detailing the results for each group of patients, the median time of serum sampling was $8,11,11,16$ and 16 days after the onset of symptoms for dead patients (PClinO3), poor outcome patients with $\mathrm{HCQ}+\mathrm{AZ}<3$ days $(\mathrm{PClinO} 2)$, poor outcome patients with $\mathrm{HCQ}+\mathrm{AZ} \geq 3$ days (PClinO1), with persistent viral shedding (PVirO) and with good outcome (GO), respectively. Rates of positive serology by group were $28 \%(8 / 29)$ in $\mathrm{PClinO} 3$ (dead), 56\% (14/25) in $\mathrm{PClinO} 2$ (HCQ+AZ $<3$ days), 49\% (26/ 53) in $\mathrm{PClinO1}$ (HCQ+AZ $\geq 3$ days), $44 \%$ (44/100) in $\mathrm{PVirO}$ (virological persistence) and 35\% (241/681) in patients with good outcome (GO). Higher rates of seropositivity were observed in group of patients with poor clinical outcome (PClinO3, PClinO2, PClinO1) compared to patients with virological persistent shedding and patients with clinical good outcome (Fig. 3) for each period time but significant results were observed after 10 days. Higher rates of seropositivity were found in $\mathrm{PClinO} 3$ (70\%), PClinO2 (71\%) and PClinO1 (57\%) compared to patients with good clinical outcome (GO) (37\%), $p=$ $0.046, p=0.01$ and $p=0.015$, respectively (Fig. $3 \mathrm{~d}$ ). In particular, the five dead patients had exhibited positive serology after day 16. No significant difference was observed between patients with persistent viral shedding (PVirO) and patient with good outcome (GO). We observed lower rate of seropositivity among the asymptomatic patients $(7 / 24,29 \%)$ compared to symptomatic patients with low NEWS score $(264 / 754,35 \%)$ but this difference was not significant, $p=0.708$. 
Fig. 2 Representation of kinetic of antibodies titre of $\operatorname{IgG}(\mathbf{a}), \operatorname{IgM}$ (b) and $\operatorname{IgA}(\mathbf{c})$ according to delay after the onset of symptoms between D0 and D30 in the different groups of patients infected with SARS-CoV-2 $(n=$ 1291). The curve represents the average values of the antibodies titre a

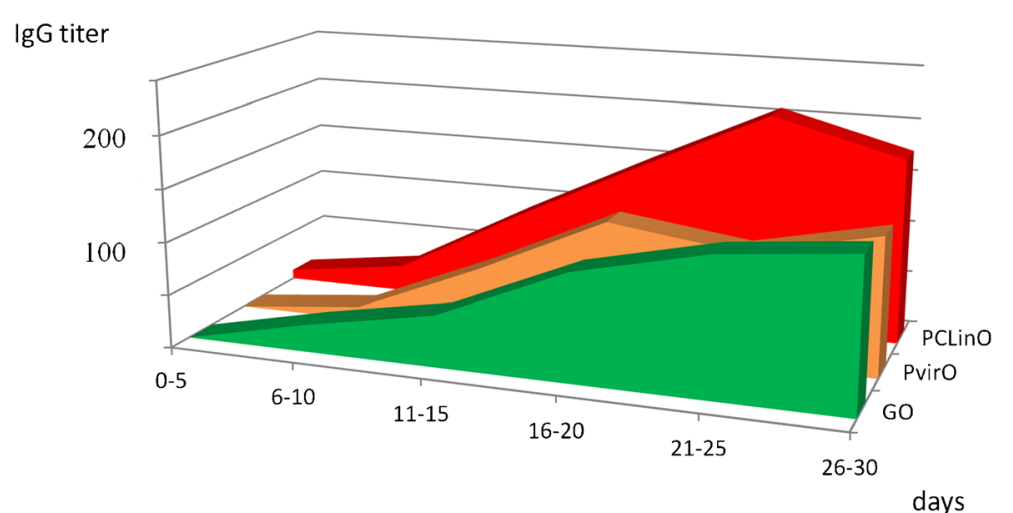

b

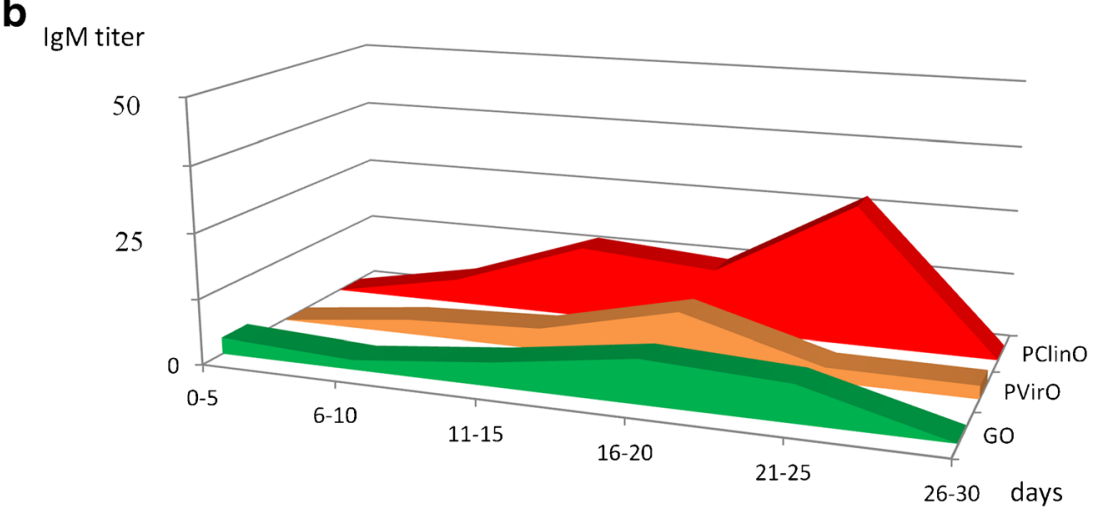

C IgA titer

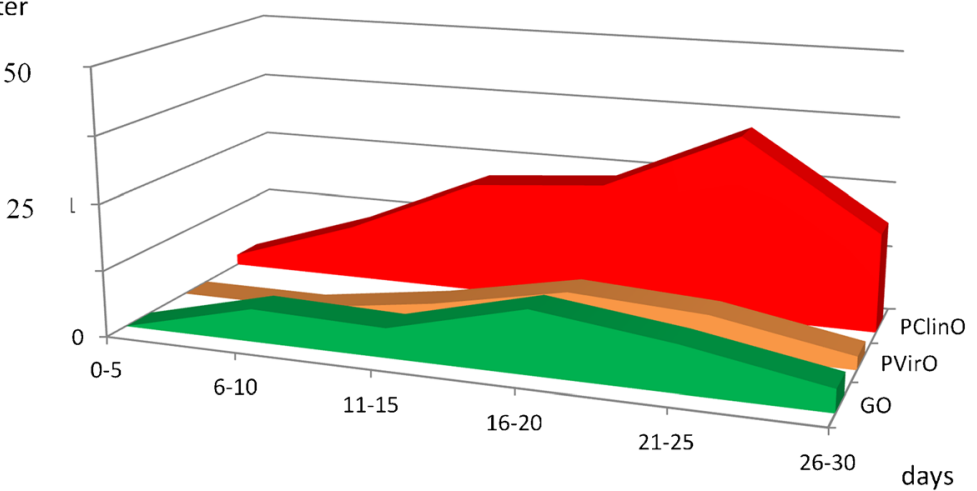

We did not observe significant difference in the time of occurrence of the different classes of antibodies from the onset of symptoms in our cohort and we noted presence of IgG in most of patients with positive serology $(n=333)$. The median of occurrence of $\operatorname{IgG}$ with titre $\geq 1: 100$ was 18 days (range $2-38$ ) and were detected in sera from 326 patients (98\%) (Table S1). IgA seems to have better sensitivity than $\operatorname{IgM}$ at the acute phase of the disease. IgM with titre $\geq 1: 50$ were detected in 42 patients $(13 \%)$ with a median of 16 days (range 6-31), and IgA with titre $\geq 1: 50$ were detected in 107 patients $(32 \%)$ with a median of 16 days (range 5-32). Three patients presented isolated $\operatorname{IgA} \geq 1: 200$ and 8 patients presented isolated $\operatorname{IgM} \geq 1: 200$ in early sera. All the other patients presented concomitant $\operatorname{IgG} \geq$ $1: 100$. We did not detail data for IgG because they were very similar to data of seropositivity including all classes of antibodies as described above. However, we observed significant higher seropositivity of IgA in patients with poor clinical outcome $(27 / 107,22 \%)$ compared to patients with persistent viral shedding (PVirO) $(11 / 100,11 \%)$ and patients with good outcome (GO) $(69 / 681,10 \%)(p=0.013$ and $p<0.0001$, respectively). For IgM, we found a significant higher prevalence in all patients with poor clinical outcome $(19 / 107,18 \%)$ and with virological persistence $(13 / 100,13 \%)$ compared to patients with good outcome $(45 / 681,7 \%)(p=0.0002$ and $p=0.038$, respectively). 
Fig. 3 Comparison of rates of seropositivity among the five groups of patients (a) between days 6 and 10, (b) between days 11 and 15 (c) between days 16 and 38 and (d) after day 10 a

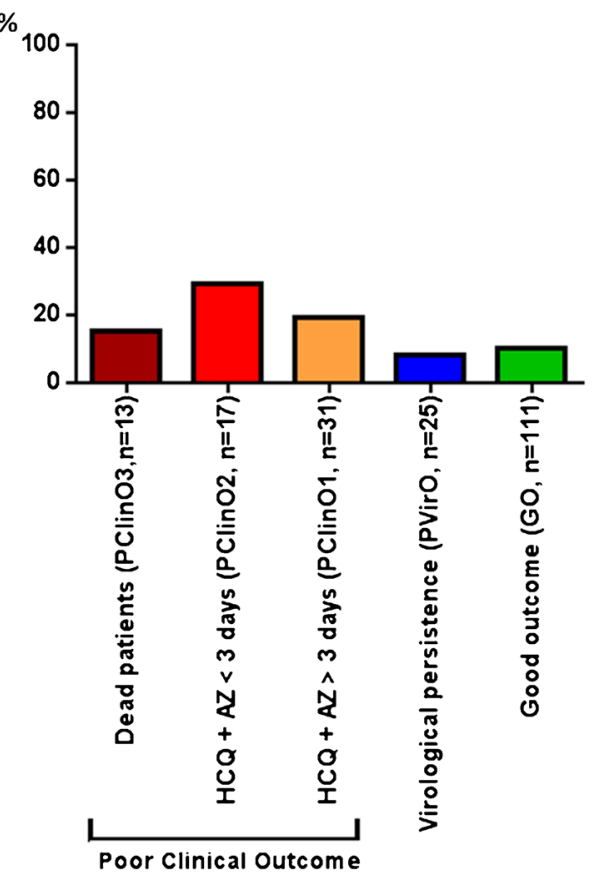

C

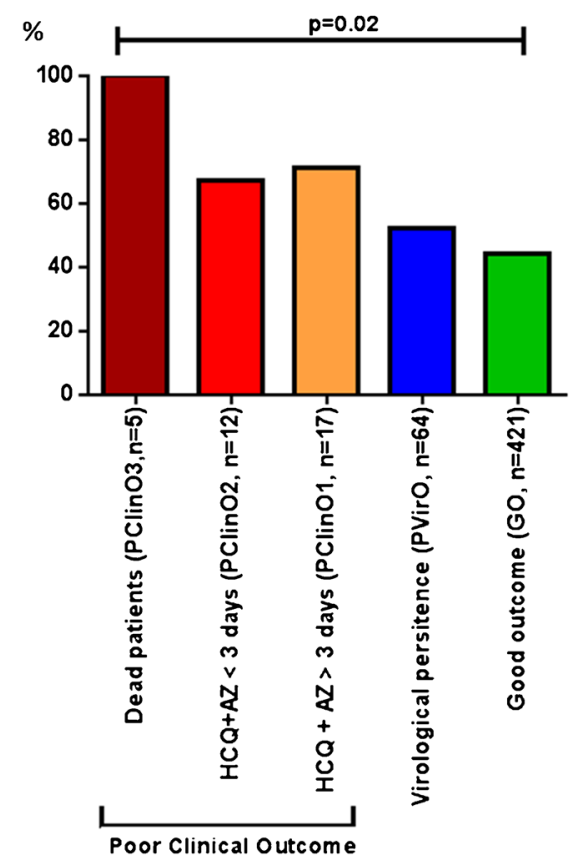

b \%

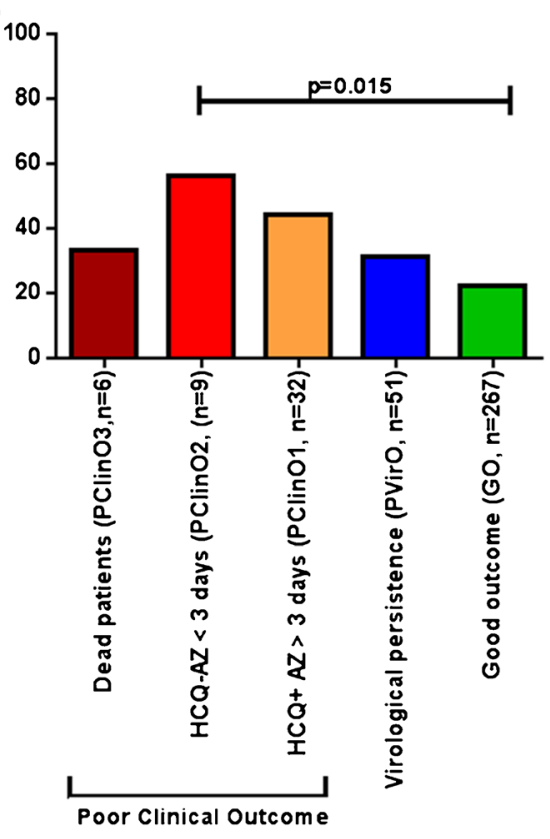

d \%

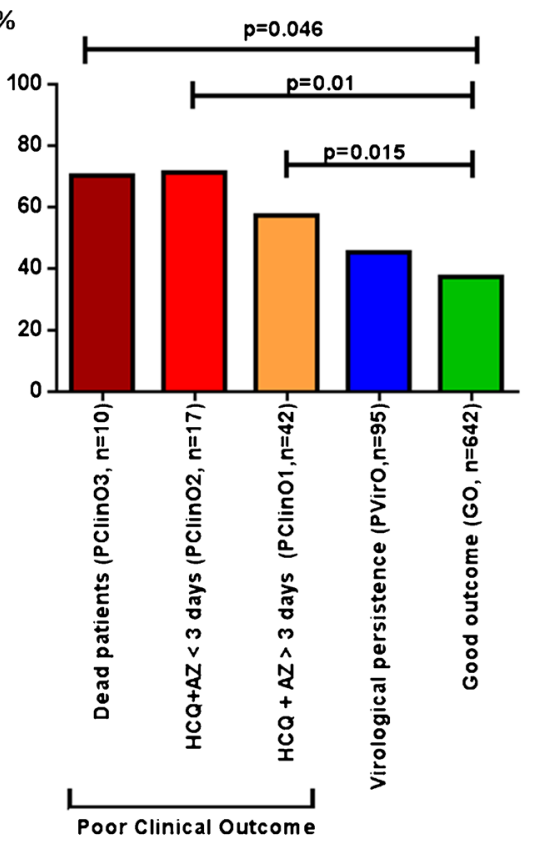

We also compared IgG titre between the five groups of patients but we included only sera collected at least 10 days after the onset of symptoms $(n=321)$. We found significant higher IgG titre in patients with a poor clinical outcome (died PClinO3, PClinO2, PClinO1) compared to patients with good outcome (GO) $(p=0.0006)$ (Fig. 4). The median of IgG titre was 1:800 for patients with poor clinical outcome and 1:200 for both patients with viral persistent shedding and patients with good outcome. We did not observed significant difference of IgM and $\operatorname{IgA}$ titre between the different groups of patients.

\section{Discussion}

To date, many methods exist for both rapid (lateral flow assays) and semi/quantitative (CLIA, ELISA) measurement of SARS-CoV-2 antibodies [13]. However, at the beginning of the pandemic, most of currently commercially available serological tests were not available for several months. In this context, we developed an in-house indirect immunofluorescence assay for the detection of IgG, IgM and IgA anti-SARSCoV-2 antibodies using SARS-CoV-2 antigen produced 


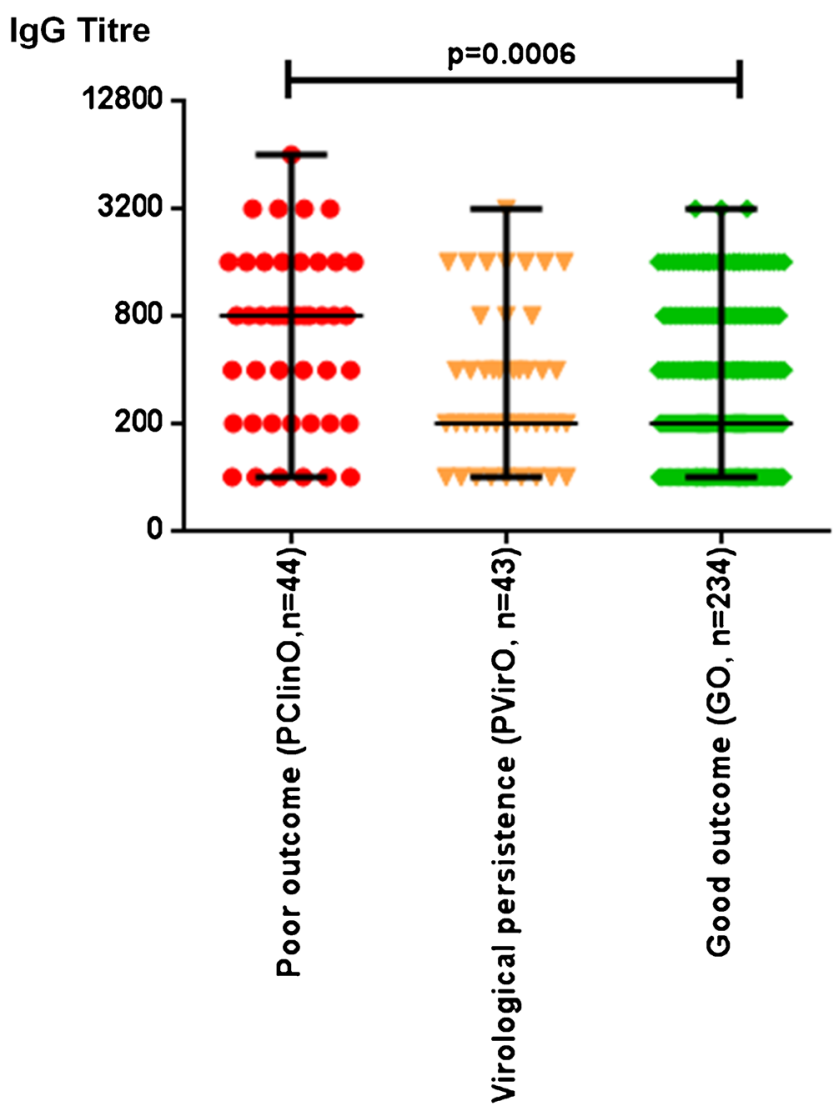

Fig. 4 Comparison of median of $\operatorname{IgG}$ titre detected at least 10 days after the onset of symptoms between the different groups of patients infected with SARS-CoV-2 (only the sera with higher IgG titre were considered for this analysis when multiple sera were available for a same patient)

directly in our biosafety level 3 laboratory. While this technique was time-consuming and could lack of standardisation, it presented the advantage to be performed only with our materials and human resources without dependence of any suppliers. We used it to assess the serological status of hundreds of COVID-19 patients and controls; as such, an assay has been only reported on a very small group of patients $[14,15]$. In order to avoid false-negative results, the assay incorporated $S$. aureus as a control of deposition of tested sera, as $S$. aureus protein A and protein $\mathrm{M}$ bind non-specifically to any serum antibody [12]. The assay also incorporated noninfected Vero cells on which the viral antigen has been produced, in order to identify false-positive reactivities. Reading of both controls was incorporated into the interpretation algorithm. Accordingly, the specificity of the assay was measured at $100 \%$ for $\operatorname{IgA}, 98.5 \%$ for $\operatorname{IgM}$ and $95.9 \%$ for $\operatorname{IgG}$. Substantial agreement was found between commercial ELISA IgG kit and our IFA technique which attests to the reliability and robustness of our in-house IFA assay compared to a standardised commercial test.

Using this assay, we observed low rates of seropositivity, at $37 \%$ in RT-qPCR-confirmed COVID-19 patients, ranging precisely from $3 \%$ before 5 days' evolution to $47 \%$ after
15 days' evolution. However, seroconversions of specific IgM and IgG antibodies were observed as early as day four after the onset of symptoms, as previously described [2]. This low rate of seropositivity is here observed in a population of treated patients with a favourable clinical evolution and outcome in most of these patients. A limit of our study is that collection of sera was not yet protocolised according to time interval after the onset of symptoms at the beginning of our study, therefore is not homogeneous time interval between the patients, and sera were analysed only at the time for which we received the sera and we did not have a kinetic for most of the patients. In contrast, we identified that patients with severe disease developed a serological response in most cases (and all patients who died) that was characterised by high levels of IgG as was also observed for SARS-CoV infection [16] and in agreement with others reports about SARS-CoV-2 infection. Most study reported higher antibody levels after a severe and critical infection than after a mild infection [17-20] especially on sera taken 7-10 days after the onset of symptoms. These findings are confirmed for different subtype of antibodies directed against S1, RBD and S2 protein [19] as well as for neutralising antibody $[19,21,22]$. Only minority of study did not find this correlation [23, 24]. Most of them include few numbers of sera or did not analysed data according to collection sample time after symptoms onset. In fact, no significant difference was mostly found on early sera [17, 18]. The discrepancies between the studies can also be explained by the nature and the target of the antigens used. Some other studies also reported an earlier serological response in severe compared to mild SARS-CoV-2 infection $[5,20$, $25]$ that is consistent with the earlier seroconversion that we found in patients with poor clinical outcome (PClinO). On the other hand, an analysis of patients with mild symptoms of COVID-19 showed that SARS-CoV-2 can persist in patients who developed specific IgG antibodies for a very long period of time, up to 28 days, whereas only one patient who did not develop an IgG response cleared the virus after 46 days [26]. Our study included a few number of asymptomatic patients. We observed lower rates of seropositivity compared to symptomatic patients but this difference was not significant; these results need to be confirmed on a larger sample size. However, most of other studies reported production of neutralising antibodies even in asymptomatic subjects but with lower antibody titre and/or delayed response than in symptomatic patients $[21,25,27,28]$.

Detecting anti-SARS-CoV-2 antibodies is useful as a marker associated with COVID-19 severity. Serology also assesses exposure to the virus, at the individual level for middle long-term medical monitoring of the patients; and at the population level for monitoring the circulation of the virus, as it is one of the markers contributing to assessing the effectiveness of countermeasures. 
Supplementary Information The online version contains supplementary material available at https://doi.org/10.1007/s10096-020-04104-2.

Acknowledgements The authors acknowledge the contribution of the technical staff of the IHU Méditerranée Infection Laboratory. This work was supported by IHU Méditerranée Infection, Marseille, France.

Authors' contributions Didier Raoult and Michel Drancourt initiated and concept the study. Sophie Edouard, Michel Drancourt, Bernard La Scola, Laurence Thomas and Fabrizio Di Pinto organised and developed the technique. Hervé Tissot-Dupont, Matthieu Million, Jean-Christophe Lagier, Andreas Stein, Philippe Parola, Philippe Brouqui and Philippe Gautret were the clinicians in charge of the patients. Sophie Edouard and Cléa Melenotte collected and interpreted the data. Sophie Edouard and Philippe Colson performed the statistical analysis. Sophie Edouard, Philippe Colson, Cléa Melenotte and Michel Drancourt drafted the manuscript. All authors amended and commented on the final manuscript.

Funding This study was funded by ANR-15-CE36-0004-01 and by ANR "Investissements d'Avenir" Méditerranée Infection 10-IAHU-03.

Data availability All relevant data are made available in the manuscript and supplementary files.

\section{Compliance with ethical standards}

Ethics approval The study was performed in accordance with the ethical standards as laid down in the 1964 Declaration of Helsinki and its later amendments. The non-interventional retrospective and anonymised nature of this study was approved by the Ethical Committee of the IHU Méditerranée Infection under no. 2020-13.

Consent to participate Not applicable

Consent to publish Not applicable

Conflict of interest The authors declare that they have no conflict of interest.

\section{References}

1. Zhu N, Zhang D, Wang W, Li X, Yang B, Song J, Zhao X, Huang B, Shi W, Lu R, Niu P, Zhan F, Ma X, Wang D, Xu W, Wu G, Gao GF, Tan W (2019) China novel coronavirus investigating and research team. A novel coronavirus from patients with pneumonia in China. N Engl J Med 382:727-733. https://doi.org/10.1056/ NEJMoa2001017

2. Xiang F, Wang X, He X, Peng Z, Yang B, Zhang J, Zhou Q, Ye H, Ma Y, Li H, Wei X, Cai P, Ma WL (2020) Antibody detection and dynamic characteristics in patients with COVID-19. Clin Infect Dis. https://doi.org/10.1093/cid/ciaa461

3. Gautret P, Lagier JC, Parola P, Hoang VT, Meddeb L, Sevestre J, Mailhe M, Doudier B, Aubry C, Amrane S, Seng P, Hocquart M, Eldin C, Finance J, Vieira VE, Dupont HT, Honoré S, Stein A, Million M, Colson P, La Scola B, Veit V, Jacquier A, Deharo JC, Drancourt M, Fournier PE, Rolain JM, Brouqui P, Raoult D (2020) Clinical and microbiological effect of a combination of hydroxychloroquine and azithromycin in 80 COVID-19 patients with at least a six-day follow up: a pilot observational study. Travel Med Infect Dis 101663. https://doi.org/10. 1016/j.tmaid.2020.101663

4. Million M, Lagier JC, Gautret P, Colson P, Fournier PE, Amrane S, Hocquart M, Mailhe M, Esteves-Vieira V, Doudier B, Aubry C, Correard F, Giraud-Gatineau A, Roussel Y, Bellenger C, Cassir N, Seng P, Zandotti C, Dhiver C, Ravaux I, Tomei C, Eldin C, Braunstein D, Tissot-Dupont H, Honoré S, Stein A, Jacquier A, Deharo JC, Chabrière E, Levasseur A, Fenollar F, Rolain JM, Obadia Y, Brouqui P, Drancourt M, La Scola B, Parola P, Raoult D (2020) Early treatment of 1061 COVID-19 patients with hydroxychloroquine and azithromycin, Marseille, France. Travel Med Infect Dis 35:101738. https://doi.org/10.1016/j.tmaid.2020. 101738

5. To KK, Tsang OT, Leung WS, Tam AR, Wu TC, Lung DC, Yip CC, Cai JP, Chan JM, Chik TS, Lau DP, Choi CY, Chen LL, Chan WM, Chan KH, Ip JD, Ng AC, Poon RW, Luo CT, Cheng VC, Chan JF, Hung IF, Chen Z, Chen H, Yuen KY (2020) Temporal profiles of viral load in posterior oropharyngeal saliva samples and serum antibody responses during infection by SARS-CoV-2: an observational cohort study. Lancet Infect Dis 20:565-574. https:// doi.org/10.1016/S1473-3099(20)30196-1

6. Bin J, Zhang Q, Ge X, Wang R, Yu J, Shan S, Zhou B, Song S, Tang X, Yu J, Ge J, Lan J, Yuan J, Wang H, Zhao J, Zhang S, Wang Y, Shi X, Liu L, Wang X, Zheng Z, Zhang L (2020) Potent human neutralizing antibodies elicited by SARS-CoV-2 infection. Nature 584:115-119. https://doi.org/10.1101/2020.03.17. 20036640

7. Guo L, Ren L, Yang S, Xiao M, Chang YF, Dela Cruz CS, Wang Y, Wu C, Xiao Y, Zhang L, Han L, Dang S, Xu Y, Yang Q, Xu S, Zhu H, Xu Y, Jin Q, Sharma L, Wang L, Wang J (2020) Profiling early humoral response to diagnose novel coronavirus disease (COVID-19). Clin Infect Dis. https://doi.org/10.1093/cid/ciaa310

8. Amrane S, Tissot-Dupont H, Doudier B, Eldin C, Hocquart M, Mailhe $\mathrm{M}$, Dudouet $\mathrm{P}$, Ormières E, Ailhaud L, Parola $\mathrm{P}$, Lagier JC, Brouqui P, Zandotti C, Ninove L, Luciani L, Boschi C, La Scola B, Raoult D, Million M, Colson P, Gautret P (2020) Rapid viral diagnosis and ambulatory management of suspected COVID19 cases presenting at the infectious diseases referral hospital in Marseille, France, - January 31st to March 1st, 2020: A respiratory virus snapshot. Travel Med Infect Dis 101632. https://doi.org/10. 1016/j.tmaid.2020.101632

9. Dupont HT, Thirion X, Raoult D (1994) Q fever serology: cutoff determination for microimmunofluorescence. Clin Diagn Lab Immunol 1:189-196

10. La Scola B, Le Bideau M, Andreani J, Hoang VT, Grimaldier C, Colson P, Gautret P, Raoult D (2020) Viral RNA load as determined by cell culture as a management tool for discharge of SARS-CoV-2 patients from infectious disease wards. Eur J Clin Microbiol Infect Dis 39:1059-1061. https://doi.org/10.1007/ s10096-020-03913-9

11. Seng P, Drancourt M, Gouriet F, La Scola B, Fournier PE, Rolain JM, Raoult D (2009) Ongoing revolution in bacteriology: routine identification of bacteria by matrix-assisted laser desorption ionization time-of-flight mass spectrometry. Clin Infect Dis 49:543-551. https://doi.org/10.1086/600885

12. Gouriet F, Levy PY, Samson L, Drancourt M, Raoult D (2008) Comparison of the new InoDiag automated fluorescence multiplexed antigen microarray to the reference technique in the serodiagnosis of atypical bacterial pneumonia. Clin Microbiol Infect 14:1119-1127

13. Lisboa Bastos M, Tavaziva G, Abidi SK, Campbell JR, Haraoui LP, Johnston JC, Lan Z, Law S, MacLean E, Trajman A, Menzies D, Benedetti A, Ahmad Khan F (2020) Diagnostic accuracy of serological tests for covid-19: systematic review and meta-analysis. BMJ 370:m2516. https://doi.org/10.1136/bmj.m2516 
14. Haveri A, Smura T, Kuivanen S, Österlund P, Hepojoki J, Ikonen N, Pitkäpaasi M, Blomqvist S, Rönkkö E, Kantele A, Strandin T, Kallio-Kokko H, Mannonen L, Lappalainen M, Broas M, Jiang M, Siira L, Salminen M, Puumalainen T, Sane J, Melin M, Vapalahti O, Savolainen-Kopra C (2020) Serological and molecular findings during SARS-CoV-2 infection: the first case study in Finland, January to February 2020. Euro Surveill 25. https://doi.org/10. 2807/1560-7917.ES.2020.25.11.2000266

15. Meschi S, Colavita F, Bordi L, Matusali G, Lapa D, Amendola A, Vairo F, Ippolito G, Capobianchi MR, Castilletti C, INMICovid-19 laboratory team (2020) Performance evaluation of Abbott ARCHITECT SARS-CoV-2 IgG immunoassay in comparison with indirect immunofluorescence and virus microneutralization test. J Clin Virol 129:104539

16. Zhang L, Zhang F, Yu W, He T, Yu J, Yi CE, Ba L, Li W, Farzan M, Chen Z, Yuen KY, Ho D (2006) Antibody responses against SARS coronavirus are correlated with disease outcome of infected individuals. J Med Virol 78:1-8

17. Zhao J, Yuan Q, Wang H, Liu W, Liao X, Su Y, Wang X, Yuan J, Li T, Li J, Qian S, Hong C, Wang F, Liu Y, Wang Z, He Q, Li Z, He B, Zhang T, Fu Y, Ge S, Liu L, Zhang J, Xia N, Zhang Z (2020) Antibody responses to SARS-CoV-2 in patients of novel coronavirus disease 2019. Clin Infect Dis ciaa344. https://doi.org/10.1093/ $\mathrm{cid} / \mathrm{ciaa} 344$

18. Liu Z-L, Liu Y, Wan L-G, Xiang T-X, Le A-P, Liu P, Peiris M, Poon LLM, Zhang W (2020) Antibody profiles in mild and severe cases of COVID-19. Clin Chem 66:1102-1104

19. Chen X, Pan Z, Yue S, Yu F, Zhang J, Yang Y, Li R, Liu B, Yang X, Gao L, Li Z, Lin Y, Huang Q, Xu L, Tang J, Hu L, Zhao J, Liu P, Zhang G, Chen Y, Deng K, Ye L (2020) Disease severity dictates SARS-CoV-2-specific neutralizing antibody responses in COVID19. Sig Transduct Target Ther 5:180

20. Okba NMA, Müller MA, Li W, Wang C, GeurtsvanKessel CH, Corman VM, Lamers MM, Sikkema RS, de Bruin E, Chandler FD, Yazdanpanah Y, Le Hingrat Q, Descamps D, HouhouFidouh N, Reusken CBEM, Bosch BJ, Drosten C, Koopmans MPG, Haagmans BL (2020) Severe acute respiratory syndrome coronavirus 2-specific antibody responses in coronavirus disease 2019 patients. Emerg Infect Dis 26. https://doi.org/10.3201/ eid2607.200841

21. Choe PG, Kang CK, Suh HJ, Jung J, Kang E, Lee SY, Song KH, Kim HB, Kim NJ, Park WB, Kim ES, Oh MD (2020) Antibody responses to SARS-CoV-2 at 8 weeks postinfection in asymptomatic patients. Emerging Infect Dis 26:2484-2487. https://doi.org/10.3201/eid2610.202211

22. Legros V, Denolly S, Vogrig M, Boson B, Rigaill J, Pillet S et al (2020) A longitudinal study of SARS-CoV-2 infected patients shows high correlation between neutralizing antibodies and COVID-19 severity http://medrxiv.org/lookup/doi/10.1101/2020. 08.27.20182493

23. Phipps WS, SoRelle JA, Li Q-Z, Mahimainathan L, Araj E, Markantonis J, Lacelle C, Balani J, Parikh H, Solow EB, Karp DR, Sarode R, Muthukumar A (2020) SARS-CoV-2 antibody responses do not predict COVID-19 disease severity. Am J Clin Pathol 154:459-465. https://doi.org/10.1093/ajcp/aqaa123

24. Liu R, Liu X, Yuan L, Han H, Shereen MA, Zhen J, Niu Z, Li D, Liu F, Wu K, Luo Z, Zhu C (2020) Analysis of adjunctive serological detection to nucleic acid test for severe acute respiratory syndrome coronavirus 2 (SARS-CoV-2) infection diagnosis. Int Immunopharmacol 86:106746. https://doi.org/10.1016/j.intimp. 2020.106746

25. Yongchen Z, Shen H, Wang X, Shi X, Li Y, Yan J, Chen Y, Gu B (2020) Different longitudinal patterns of nucleic acid and serology testing results based on disease severity of COVID-19 patients. Emerg Microbes Infect 1-14. https://doi.org/10.1080/22221751. 2020.1756699

26. Wang B, Wang L, Kong X, Geng J, Xiao D, Ma C, Jiang X, Wang P-H (2020) Long-term coexistence of severe acute respiratory syndrome coronavirus 2 (SARS-CoV-2) with antibody response in coronavirus disease 2019 (COVID-19) patients. J Med Virol. https://doi.org/10.1002/jmv.25946, https://doi.org/10.1101/2020. 04.13.20040980

27. Wang X, Guo X, Xin Q, Pan Y, Li J, Chu Y, Feng Y, Wang Q (2020) Neutralizing antibodies responses to SARS-CoV-2 in COVID-19 in patients and convalescent patients. Clin Infect Dis ciaa721. https://doi.org/10.1093/cid/ciaa721

28. Ko J-H, Joo E-J, Park S-J, Baek JY, Kim WD, Jee J, Kim CJ, Jeong C, Kim YJ, Shon HJ, Kang ES, Choi YK, Peck KR (2020) Neutralizing antibody production in asymptomatic and mild COVID-19 patients, in comparison with pneumonic COVID-19 patients. J Clin Med 9:2268

Publisher's note Springer Nature remains neutral with regard to jurisdictional claims in published maps and institutional affiliations. 